\title{
The nature of iodine oxygen bonds in hypervalent 10-I-3 iodine compounds
}

\author{
Paul Kiprof* \\ Department of Chemistry, University of Minnesota Duluth, Duluth, MN 55812, USA. \\ E-mail: pkiprof@d.umn.edu
}

\section{Dedicated to Professor Nikolai Zefirov on the occasion of his $70^{\text {th }}$ birthday}

(received 26 July 04; accepted 23 Sep 04; published on the web 14 Oct 04)

\begin{abstract}
Iodine oxygen bonds of hypervalent 10-I-3 iodine(III) compounds with T-shaped geometry were investigated using analysis of the Cambridge Crystallographic Database and ab initio molecular orbital calculations. The statistical analysis of the I-O bond lengths revealed an average of 2.14 $\AA$ and a strong correlation between the two bond lengths.
\end{abstract}

Keywords: Hypervalent iodine, ab initio, density functional, iodine oxygen bonding

\section{Introduction}

There has been great interest in hypervalent iodine chemistry because of the use of hypervalent iodine compounds for a variety of organic transformations. ${ }^{1}$

At the same time, theoretical calculations concerning the reactivity of these compounds have not kept pace with the rapid development in their synthesis and applications. ${ }^{2}$

In addition to regular covalent bonds, hypervalent covalent bonds and secondary bonding are crucial for these compounds. While the nature of hypervalent covalent bonds can be related to regular covalent bonds, secondary bonding is unlike in its nature to dative bonding and hydrogen bonding but has very similar consequences concerning the aggregation of hypervalent iodine compounds. In a previous paper, we investigated the effect of secondary bonding in the molecular assembly of iodine compounds. ${ }^{2}$

Typically, hypervalent 10-I-3 iodine(III) compounds exhibit a T-shaped geometry with the more electropositive substituent on the iodine in the equatorial position which is the base of the "T." The two other, more electronegative, substituents occupy the axial positions, which are the wings in the "T."

In the hypervalent bonding model, the axial substituents share their interaction with the same iodine orbitals, mainly the iodine $p_{z}$ orbital and s orbital. Because of this, the bonding of one 
axial substituent is connected to the bonding of the other axial substituent, resulting in a "hypervalent trans effect." Based on this discussion, in hypervalent phenyl iodine compounds of the composition $\mathrm{Ph}-\mathrm{IX}_{2}$, the more electronegative $\mathrm{X}$ substituents end up in the axial positions and influence each other's bonding.

We have therefore studied the system $\mathrm{Ph}-\mathrm{I}(\mathrm{OR})_{2}$ by statistical crystallography methods and theoretical investigation in order to describe and understand the effect of one axial substituent on the other in terms of the hypervalent trans effect.

To this end, we created a subset of the Cambridge Structural Database (CSD) ${ }^{3}$ containing hypervalent iodine(III) compounds which followed the general structural pattern " $\mathrm{Ph}-\mathrm{I}(\mathrm{OR})_{2}$ " with a T-shaped geometry (Figure 1).

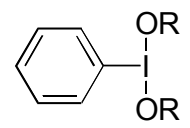

Figure 1. Structure pattern for the CSD search.

\section{Results and Discussion}

A histogram in which every bond length is counted (two bond lengths per compound) revealed that the mean value for the I-O bond in this class of compounds is $2.14 \AA$ (Figure 2).

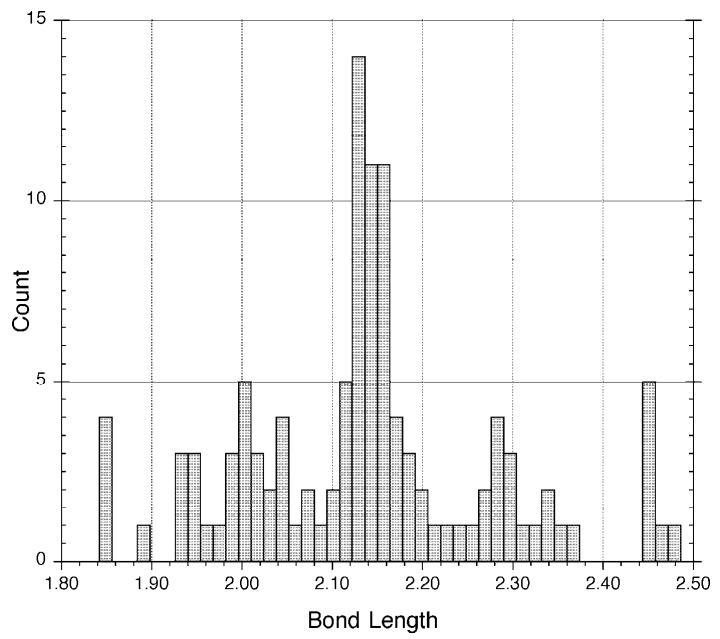

Figure 2. Histogram plot of I-O bond lengths.

The values range from $1.842 \AA$ to $2.474 \AA$. In order to further investigate the I-O bond length distribution, a scatter diagram was plotted where one I-O bond length is plotted against the other 
(Figure 3). The two bond lengths show a strong negative correlation of -0.93 . In essence, the shorter one I-O bond is the longer the other will be and vice versa.

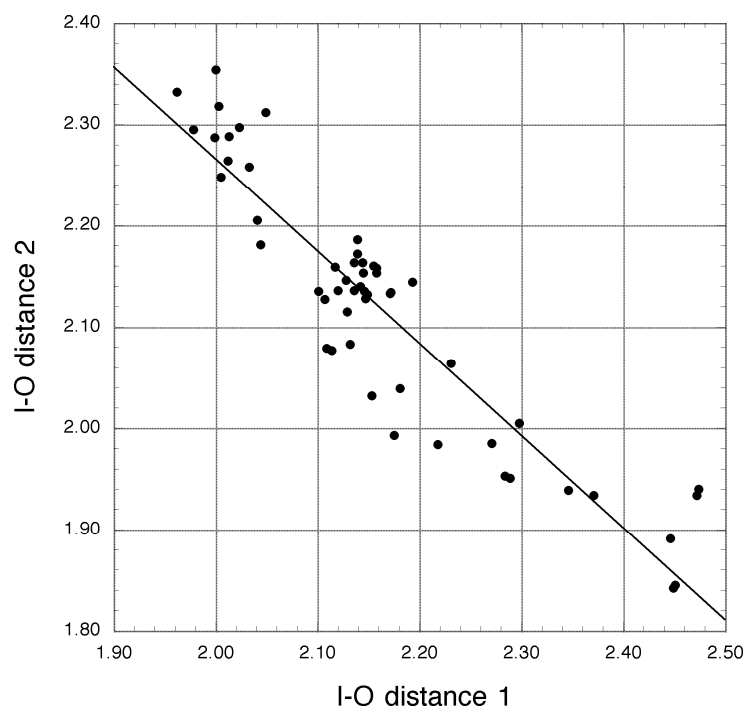

Figure 3. Scatter diagram of the I-O distances with the best linear fit.

The data in Figure 2 can be fitted into a linear equation

$$
\mathrm{IO}_{1}=4.2815 \AA-\mathrm{IO}_{2}
$$

with an $\mathrm{R}^{2}$ value of 0.87 reflecting the average value of $2.14 \AA\left(\mathrm{IO}_{1}+\mathrm{IO}_{2}=\right.$ constant $=2 \times 2.14$ $\AA$ ). A better linear fit is achieved by the equation

$$
\mathrm{IO}_{1}=4.0865 \AA-0.91027 \mathrm{IO}_{2}
$$

with an $\mathrm{R}^{2}$ value of 0.88 .

In order to investigate the nature of a variety of iodine oxygen bonds three examples were chosen that have a variation of the covalent/ionic character of the trans substituent (Scheme 1)

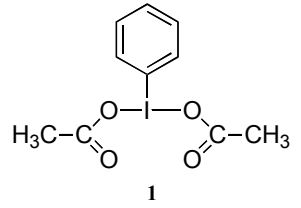

Scheme 1
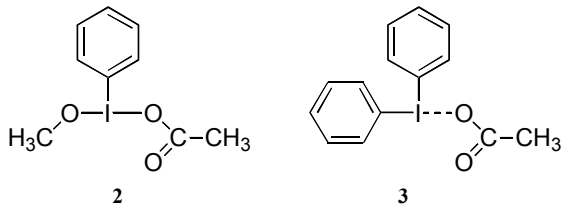

3<smiles>CC(=O)OI(O)c1ccccc1</smiles>

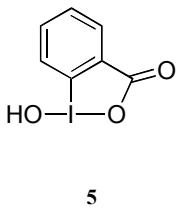


Compound $\mathbf{1}$ has the same types of I-O bonds whereas in 2, $\mathbf{4}$ and $\mathbf{5}$ a more covalent I-O bond is present with the methoxy and hydroxy group. Compound $\mathbf{3}$ is an iodonium salt with acetate as an anion and should have mostly ionic character of the I-O bond. The structures are in fairly good agreement with experimental data where crystallographic data is available.

Natural charges and the Wiberg bond indices were calculated to examine the covalent/ionic character of the I-O bonds. In compounds 1, 2, 4 and 5 where iodine is bonded to two oxygen atoms the charge is higher than for compound $\mathbf{3}$ (Figure 4 ).

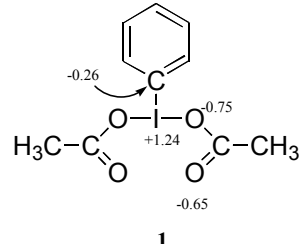

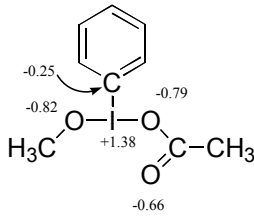

2

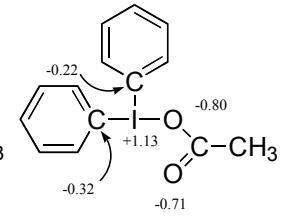

3

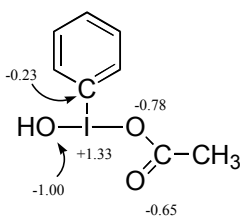

4

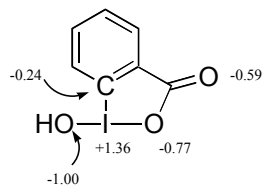

5

Figure 4. Selected natural charges of the compounds.

While the charges on iodine, carbon and oxygen change only slightly between the compounds, the changes of the bond indices are reflecting the change of the I-O(acetate) bond towards more ionic and less covalent. The bond indices decrease from 0.41 to 0.38 and 0.23 for 3, which is formally diphenyl iodonium acetate. This coincides with an increase in the calculated bond lengths $2.20 \AA, 2.22 \AA$ and $2.37 \AA$. For the methoxy oxygen atom, the opposite effect is observed. The bond distance decreases to $2.07 \AA$ and the bond. Similar values as in 2 are observed for $\mathbf{4}$ and $\mathbf{5}$. Although compound $\mathbf{5}$ is a heterocyclic compound it gives very similar values to the acyclic compounds (Figure 5).<smiles>CC[I-](OC(C)=O)(OC(C)=O)c1ccccc1</smiles>

1

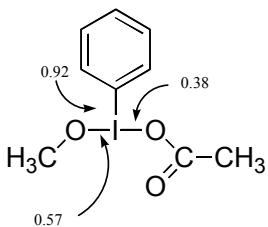

2

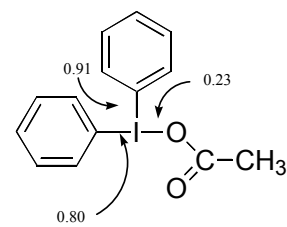

3

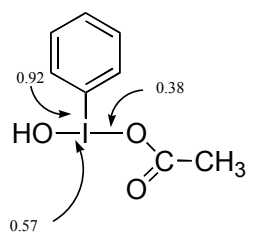

4

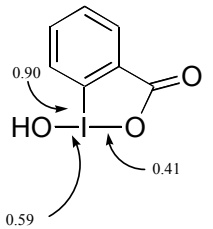

5

Figure 5. Selected Wiberg bond indices from the NBO calculation.

The bond indices are, independent of the compound correlated to the bond length, essentially, the shorter the bond length, the higher the bond index (Figure 6). 


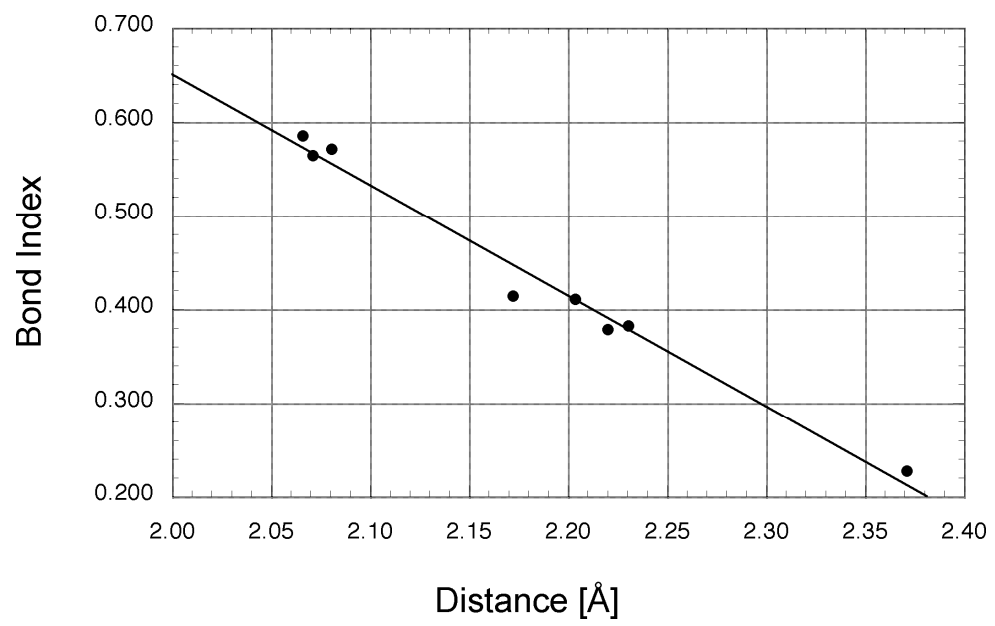

Figure 6. Plot of calculated I-O distances vs. Wiberg bond index with linear fit line $\left(\mathrm{R}^{2}=0.982\right)$.

\section{Conclusions}

We have investigated iodine oxygen bonding by analyzing crystallographic data and molecular orbital calculations. In the analysis of the crystallographic data of structures fitting the pattern $\mathrm{Ph}-\mathrm{I}(\mathrm{OR})_{2}$ it was fond that, in a T-shaped geometry, the two iodine oxygen axial bond lengths are coupled and influence each other. The MO theoretical calculations confirmed this fact to a broader range of compounds. The bond indices of the compounds give further insight into this fact.

\section{Experimental Section}

Database search. A subset of the Cambridge Structural Database (CSD) ${ }^{3}$ containing compounds with the general structural pattern "Ph-I $(\mathrm{OR})_{2}$ " and a T-shaped geometry and superstructures thereof was compiled using the programs Quest and ConQuest. ${ }^{4}$ All included compounds were hypervalent iodine(III) derivatives. If a structure contained crystallographically independent molecules or multiple iodine centers, all I-O bond lengths were used. Histograms of the I-O distances were compiled based on the structural data of this database subset and scattering diagrams which show the dependence of one I-O bond on the other were plotted. A covariance analysis of all structural parameters was also performed. Initial plots and analyses were made using the program Vista.

Molecular orbital calculations. The theoretical investigation was done using the Gaussian 94, Gaussian 98, and Gaussian 03 program systems ${ }^{5,6,7}$ and the NBO 5.0 program package ${ }^{8}$ was employed for the analysis of the bonding and charges. The hybrid density functional method 
B3LYP was used as implemented in Gaussian with the effective core potential basis set for iodine LANL2DZ by Hay and Wadt ${ }^{9}$ augmented with one $d$ function and $p$ function ${ }^{9}$. The basis sets of the remaining elements consisted of the $6-311(++) G(d, p)$ basis sets of these elements as implemented in Gaussian. The size of the studied compounds allowed us to use a slightly larger basis set than previously. ${ }^{3 \mathrm{~b}}$ The geometry optimization of the structures was performed at this level of theory and the NBO analysis performed afterwards on the optimized structures.

\section{Acknowledgements}

We would like to thank the Supercomputing Institute for Digital Simulation and Advanced Computation of the University of Minnesota and the Visualization and Digital Imaging Laboratory at the University of Minnesota Duluth for valuable computer resources.

\section{References and Notes}

1. (a) Varvoglis, A. Hypervalent Iodine in Organic Synthesis, Academic Press: London 1997.

(b) Stang, P. J.; Zhdankin, V. V. Chem. Rev. 1996, 96, 1123. (c) Zhdankin, V. V.; Stang, P. J. Chem. Rev. 2002, 102, 2523.

2. (a) Zhdankin, V. V.; Arbit, R. M.; Lynch, B. J.; Kiprof, P.; Young, V. G. Jr. J. Org. Chem. 63, 1998, 6590. (b) Kiprof, P.; Zhdankin, V.V. ARKIVOC 2003, (vi), 170.

3. Allen, F. H. Acta Crystallogr. B58, 380.

4. Bruno, J. ; Cole, J. C.; Edgington, P. R.; Kessler, M.; Macrae, C. F.; McCabe, P.; Pearson, J.; Taylor, R. Acta Crystallogr. 2002, B58, 389.

5. Gaussian 94, Revision E.2, Frisch, M. J.; Trucks, G. W.; Schlegel, H. B.; Johnson, B.; Robb, M. A.; Cheeseman, J. R.; Keith, T.; Petersson, G.A.; Montgomery, J. A. Jr.; Raghavachari, K.; Al-Laham, M. A.; Zakrzewski, V. G.; Ortiz, J. V.; Foresman, J. B.; Cioslowski, J.; Stefanov, B. B.; Nanayakkara, A.; Challacombe, M.; Peng, C. Y.; Ayala, P. Y.; Chen, W.; Wong, M. W.; Andres, J. L.; Replogle, E. S.; Gomperts, R.; Martin, R. L.; Fox, D. J.; HeadGordon, M.; Gonzalez, C.; Pople, J.A., Gaussian, Inc., Pittsburgh, PA, 1995.

6. Gaussian 98, Revision A.3, Frisch, M. J.; Trucks, G. W.; Schlegel, H. B.; Scuseria, G. E.; Robb, M. A.; Cheeseman, J. R.; Zakrzewski, V. G.; Montgomery, Jr., J. A.; Stratmann, R. E.; Burant, J. C.; Dapprich, S.; Millam, J. M.; Daniels, A. D.; Kudin, K. N.; Strain, M. C.; Farkas, O.; Tomasi, J.; Barone, V.; Cossi, M.; Cammi, R.; Mennucci, B.; Pomelli, C.; Adamo, C.; Clifford, S.; Ochterski, J.; Petersson, G. A.; Ayala, P. Y.; Cui, Q.; Morokuma, K.; Malick, D. K.; Rabuck, A. D.; Raghavachari, K.; Foresman, J. B.; Cioslowski, J.; Ortiz, J. V.; Stefanov, B. B.; Liu, G.; Liashenko, A.; Piskorz, P.; Komaromi, I.; Gomperts, R.; Martin, R. L.; Fox, D. J.; Keith, T.; Al-Laham, M. A.; Peng, C. Y.; Nanayakkara, A.; Gonzalez, C.; Challacombe, M.; Gill, P. M. W.; Johnson, B.; Chen, W.; Wong, M. W.; 
Andres, J. L.; Gonzalez, C.; Head-Gordon, M.; Replogle, E. S.; Pople, J. A. Gaussian, Inc., Pittsburgh PA, 1998.

7. Gaussian 03, Revision B.5, Frisch, M. J.; Trucks, G. W.; Schlegel, H. B.; Scuseria, G. E.; Robb, M. A.; Cheeseman, J. R.; Montgomery, Jr., J. A.; Vreven, T.; Kudin, K. N.; Burant, J. C.; Millam, J. M.; Iyengar, S. S.; Tomasi, J.; Barone, V.; Mennucci, B.; Cossi, M.; Scalmani, G.; Rega, N.; Petersson, G. A.; Nakatsuji, H.; Hada, M.; Ehara, M.; Toyota, K.; Fukuda, R.; Hasegawa, J.; Ishida, M.; Nakajima, T.; Honda, Y.; Kitao, O.; Nakai, H.; Klene, M.; Li, X.; Knox, J. E.; Hratchian, H. P.; Cross, J. B.; Adamo, C.; Jaramillo, J.; Gomperts, R.; Stratmann, R. E.; Yazyev, O.; Austin, A. J.; Cammi, R.; Pomelli, C.; Ochterski, J. W.; Ayala, P. Y.; Morokuma, K.; Voth, G. A.; Salvador, P.; Dannenberg, J. J.; Zakrzewski, V. G.; Dapprich, S.; Daniels, A. D.; Strain, M. C.; Farkas, O.; Malick, D. K.; Rabuck, A. D.; Raghavachari, K.; Foresman, J. B.; Ortiz, J. V.; Cui, Q.; Baboul, A. G.; Clifford, S.; Cioslowski, J.; Stefanov, B. B.; Liu, G.; Liashenko, A.; Piskorz, P.; Komaromi, I.; Martin, R. L.; Fox, D. J.; Keith, T.; Al-Laham, M. A.; Peng, C. Y.; Nanayakkara, A.; Challacombe, M.; Gill, P. M. W.; Johnson, B.; Chen, W.; Wong, M. W.; Gonzalez, C.; and Pople, J. A.; Gaussian, Inc., Pittsburgh PA, 2003.

8. NBO 5.0. Glendening, E. D.; Badenhoop, J. K.; Reed, A. E.; Carpenter, J. E.; Bohmann, J. A.; Morales, C. M.; Weinhold, F. (Theoretical Chemistry Institute, University of Wisconsin, Madison, WI, 2001); http://www.chem.wisc.edu/ nbo5

9. Hay, P. J.; Wadt, W. R. J. Chem. Phys. 1985, 82, 284.

10. Check, C. E.; Faust, T.O.; Bailey, J.M.; Wright, B.J.; Gilbert, T.M.; Sunderlin, L.S. J. Phys. Chem. A 2001, 105, 8111. Basis sets were obtained from the Extensible Computational Chemistry Environment Basis Set Database, Version 02/25/04, as developed and distributed by the Molecular Science Computing Facility, Environmental and Molecular Sciences Laboratory which is part of the Pacific Northwest Laboratory, P.O. Box 999, Richland, Washington 99352, USA, and funded by the U.S. Department of Energy. The Pacific Northwest Laboratory is a multi-program laboratory operated by Battelle Memorial Institute for the U.S. Department of Energy under contract DE-AC06-76RLO 1830. 